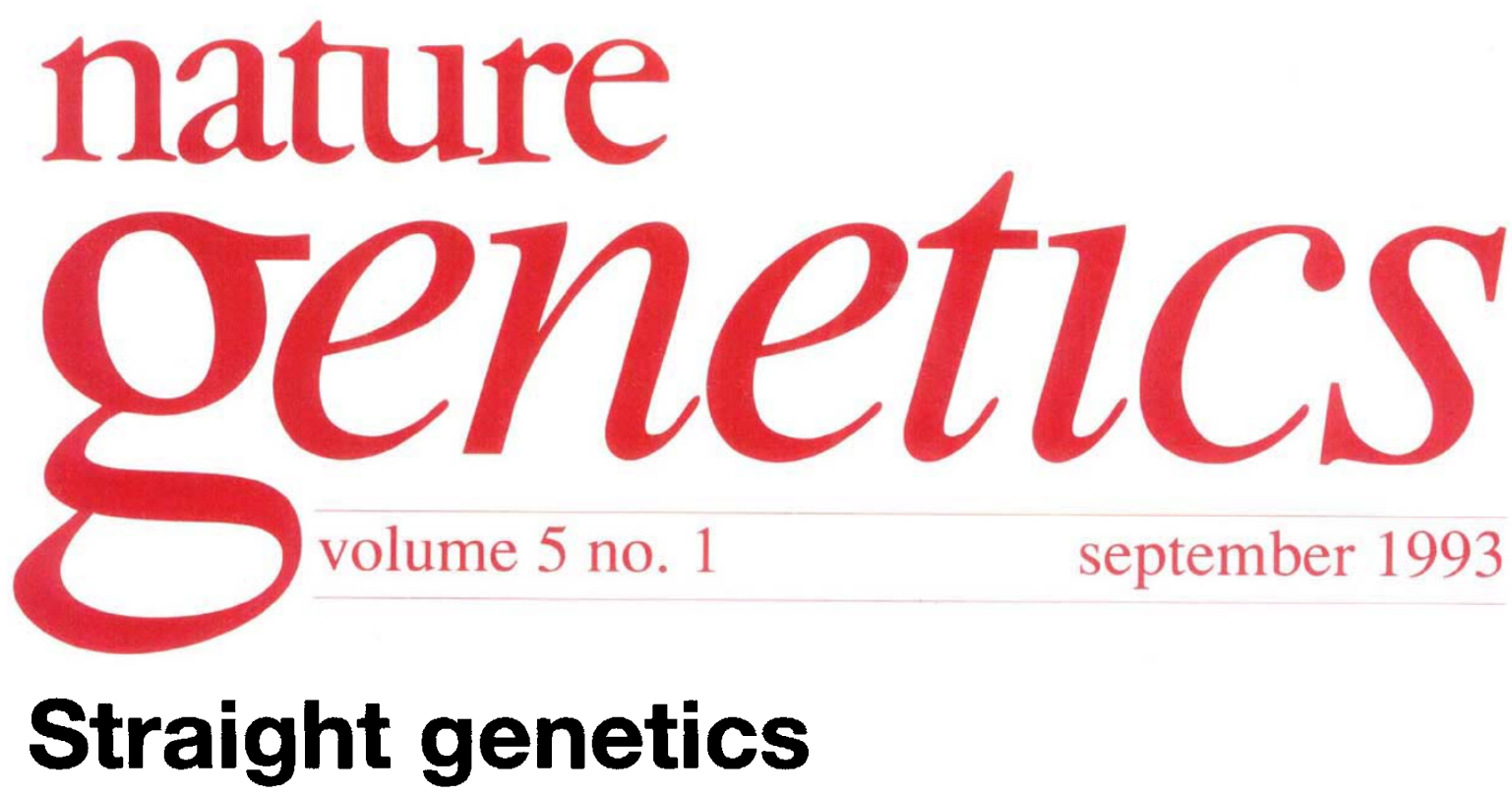

The recent report of linkage between chromosome $\mathrm{X}$ sequences (genes?) and male homosexuality has predictably led to a deluge of comment. Unfortunately, much of this comment has concentrated on the politics of homosexuality and all but ignored the nature of the scientific report. The paper ${ }^{1}$ describes significant linkage between Xchromosome markers and male homosexuality in a group of 40 pairs of homosexual brothers and reports that a genetic influence is almost certain in some types of sexual orientation. The general press has devoted many column inches to discussion on the way in which this report is received by different lay groups within the community. The result has been to dramatize what is a simple and undramatic report.

Much genetic research is of course conducted with a specific aim. For example, disease genes are sought to help minimize the suffering of those in any way affected by them. The outcome may make accurate diagnosis possible or result in a more complete understanding of

Does the media largely ignore the science in favour of the drama? the pathogenesis of a condition, a successful treatment or occasionally even a cure. Whether the homosexuality gene has practical value remains to be seen, but there is no doubt that it has enormous scientific interest. The fact that, in some, male homosexuality is inherited stimulates other absorbing questions. By what means, for example? And what other behavioural traits may people inherit? For the time being, these are the questions provoked by Hamer $e t$ al. Thus all the speculation about the possible abuse of what is still more a clue to the complexity of the human genome than the identification of a gene is misplaced. Thus all the speculation on possible abuse of what is still only potential genetic information on sexuality is misplaced. We would be better served by an evaluation of the techniques used, how the results can and can not be interpreted and the next research step in an interesting science story.

So what of the next step in what is undoubtedly an interesting story, albeit one of many? Dean Hamer and his colleagues at the National Cancer Institute in Maryland are the first to admit that the findings presented in their paper in Science are preliminary, from the point of view of demonstrating a clear genetic influence on homosexuality. Final proof must await the identification of a gene sequence, and the next step in achieving that (if it is there to be achieved) is the replication and confirmation of these initial findings. Whereas a correlation carrying a lod score (logarithm of the odds ratio) of 4 (as reported by Hamer et al.) is a strong indicator of linkage, it is possible that this correlation may disapppear on closer examination of a larger sample. Clearly, many more families must be studied, and this work is in progress. Also in progress is a wider search for associations that might account for the seven pairs of homosexual brothers that did not inherit the marker linked with the other 33 pairs. Sib pairs discordant for the identified chromosome-Xq28 associations will also be useful in identifying other (nongenetic) factors. The sample analysed in the present study was highly selected (only self- 
identified homosexual brother pairs who volunteered to take part are represented) and thus does not purport to represent other homosexual men. The study must therefore be widened to other homosexual and heterosexual men to help define the extent of the association.

Finally, this study has no bearing on female homosexuality. Hamer and colleagues are also pursuing a line of investigation aimed at defining similar correlations in this group. The male study benefited from an observed tendency for female transmission of the homosexual trait. This observation immediately suggested X-chromosome transmission and provided a rationale for screening homosexual brothers for common inheritance of $\mathrm{X}$-chromosome sequences. Unfortunately, this option is not available for the study of a female trait, so Hamer and colleagues will initiate a genomewide search for an equivalent female association.

No doubt this move will also promote an inappropriate response from much of the media. Just as over-dramatizing the supposed effects of the male homosexuality linkage serves no useful purpose, neither do arguments on the extent of genetic influences on homosexuality. In a recent commentary published in the New York Times, Ruth Hubbard (professor emeritus of biology, Harvard University) attempts to discredit the associations between homosexuality and genetics by pointing out the limitations of such study. This is a surprising thing to do, as the limitations were made abundantly clear by the authors. Hubbard seems to be worried that society at large will hear of the recent advances being made in the genetic studies of polygenic and multifactorial traits and assume that each step of each investigation is a fait accompli with an immediate potential diagnostic implication. But this disregards the unambiguous and proven method of calculating the statistical likelihood that an association is real as opposed to one that has come about by chance and simply reflects a sporadic chance occurrence. Thus when Hamer and colleagues report that the observed association between certain $\mathrm{X}$-chromosome markers and homosexual behaviour is quantified as carrying a lod score of 4.0 , this simply means that there is 1 in 10,000 chance that the observed association is due to a statistical anomaly rather than to a real (and genetic) effect in the group studied.

This result is not, as some commentators have suggested, a breakthrough in our understanding of sexuality, nor does it promise to eradicate discrimination against homosexuals or claim to be the basis of a new set of civil rights laws. It is an interesting and stimulating result that suggests that further investigation into the potentially inherited component of sexuality may advance understanding. It is also straight genetics and should be valued as such.

\section{Cardiomyopathy revisited}

In the July's Nature Geneticseditorial, the complexity and heterogeneity of cardiomyopathic disorders were discussed in the context of the professional basketball player and celebrity, Reggie Lewis. A dispute had arisen between senior cardiologists about the reason for the collapse of Lewis during a crucial play-off last April. The original diagnosis of hypertrophic cardiomyopathy (which threatened to end the athlete's career) was later questioned by Gilbert Mudge (Brigham and Women's Hospital) who suggested that Lewis had an essentially normal and healthy heart but was subject to a neurocardiogenic syncope, a relatively benign condition. Tragically, on July 27, Lewis died during mild exercise and just three months after his much publicized collapse. Early post-mortem reports describe an enlarged and extensively scarred heart, thus fueling the dispute. Certainly, these findings suggest that the second diagnosis of a neurological condition was at best incomplete and have unfortunately resulted in fans of Lewis making a target of Mudge. The whole episode serves to emphasize the complexity of diagnosing heart conditions but perhaps more important reinforces what we also know but often ignore - medicine is an incomplete science that often requires further collaborative study rather than open and public bickering over what are necessarily difficult diagnoses. Rather than continuing the unsightly and needless dispute over who was right and who was wrong, the eminent cardiologists involved (and others) would serve the community better by acknowledging the difficulties and educating a public that could be forgiven for believing that if sufficient funds are available to hire any number of leading physicians, the correct diagnosis can always be made for any condition. It cannot.

\section{References}

1. Hamer, D.H. Science 261, 321-327 (1993) 